\title{
EVALUATION OF LUMBAR SPINE LOAD BY COMPUTATIONAL METHOD IN ORDER TO ACKNOWLEDGE LOW-BACK DISORDERS AS OCCUPATIONAL DISEASES
}

\author{
Jana Hlávková1, Tomáš Lebeda1, Tomáš Tichý1, Petr Gad’ourek4, Pavel Urbann ${ }^{1,3}$, Marie Nakládalová2, \\ Andrea Laštovkováa, Zdenka Fenclová3, Petr Ridzoň ${ }^{3,7}$, Edvard Ehler $^{5}$, Milan Richter $^{6}$, Lenka Pešáková8, \\ Daniela Pelclová ${ }^{3}$ \\ ${ }^{1}$ National Institute of Public Health, Prague, Czech Republic \\ ${ }^{2}$ Department of Occupational Medicine, Medical Faculty, University of Palacký in Olomouc and General University Hospital in Olomouc, \\ Olomouc, Czech Republic \\ ${ }^{3}$ Department of Occupational Medicine, First Medical Faculty, Charles University and General University Hospital, Prague, Czech Republic \\ ${ }^{4}$ GETA Centrum, Prague, Czech Republic \\ ${ }^{5}$ Department of Neurology, Regional Hospital, Pardubice, Czech Republic \\ ${ }^{61 s t}$ Department of Orthopaedics, First Medical Faculty, Charles University and Motol University Hospital, Prague, Czech Republic \\ ${ }^{7}$ Thomayer's Hospital, Prague, Czech Republic \\ ${ }^{8}$ Regional Public Health Institute, Olomouc, Czech Republic
}

\section{SUMMARY}

Aim: The aim of the study was to develop a computational module for the prediction of compressive force on the L4/L5 disc suitable for use in field settings.

Method: The value of compressive force is intended to be used as a proxy measure of the mechanical burden of low-back when performing work activities. The compressive force predicted by the module in a particular worker should be compared with the NIOSH limit value of 3,400 N for the assessment of lumbar spine load during manual lifting tasks. Exceeding the limit will be considered as the fulfilment of "hygienic criterion" that should be met to acknowledge low-back disorder as an occupational disease. To develop the computational module we used the ergonomic software TECNOMATIX Classic Jack taking into account the anthropometric parameters of a worker and ergonomic parameters of his/her work activity.

Results: We calculated compressive forces on the $L 4 / L 5$ disc in about 1,300 simulated combinations of various factors influencing compressive force. Parameters which turned out to be crucial for the compression of $L 4 / L 5$ disc were included in the computational algorithm.

Conclusion: Our study was primarily aimed at the assessment of lumbar disorders as occupational diseases. Moreover, the study can contribute to the recommendation of preventive measures to decrease health risks in occupations associated with the overload of low-back region. The graphic maps generated by the computational module enable a fast and exact analysis of particular job.

Key words: low-back disorders, low-back pain, compressive force, manual lifting, lumbar spine load assessment, biomechanical analysis, ergonomic software, trunk posture, evaluation, prediction, time, frequency, criteria, prevention

Address for correspondence: J. Hlávková, National Institute of Public Health, Šrobárova 48, 10042 Prague, Czech Republic. E-mail: jana. hlavkova@szu.cz

http://dx.doi.org/10.21101/cejph.a4332

\section{INTRODUCTION}

Lumbar spine disorders, such as low-back pain or sciatica, are frequent in the general population. Their lifetime prevalence is estimated as high as $60-85 \%(1-4)$. The aetiology of dorsopathies is multifactorial. Many factors can contribute to their occurrence: individual, psychosocial and physical including risk factors associated with work.

Occupational risk factors for the lumbar spine include handling and lifting heavy loads, frequent bending and twisting, awkward work postures, and exposure to whole-body vibration. In the metaanalysis of 40 epidemiologic studies (5), the relationship between dorsopathies and exposure to occupational risk factors associated with manual handling was estimated as OR $1.54(95 \%$ CI 1.31-1.74), for frequent bending and twisting OR 1.68 (95\% CI 1.41-2.01), and for whole body vibration OR 1.39 (95\% CI $1.24-1.55)$.

The dorsopathies with prevailing occupational aetiology are considered to be occupational diseases with entitlement to compensation. The European Schedule of Occupational Diseases (6) includes two items related to dorsopathies (Annex II, Item 2.5.1: "Avulsion due to overstraining of the spinous processes", and 
Item 2.5.2: "Disc-related diseases of the lumbar vertebral column caused by the repeated vertical effects of whole-body vibration"). In agreement with the Recommendation, the dorsopathies can be acknowledged as occupational diseases and compensated in some EU member states (e.g., in Belgium, Bulgaria, Denmark, France, Italy, Romania, Slovak Republic, Slovenia, and Spain), but not in the Czech Republic. However, adding low-back disorders to the Czech List of Occupational Diseases (7) (hereinafter the List) is being considered. As a prerequisite the criteria for acknowledgement have to be defined. They should be determined in such a way that they make possible to acknowledge a disease as occupational in well-established cases but at the same time prevent misuse of the system.

According to the Czech legislation, two necessary conditions must be met before a disease enumerated in the List can be acknowledged as occupational: the exact diagnosis must be established (clinical criterion) and relevant exposure must be proved (hygienic criterion). To comply with the Czech system of occupational diseases, the criteria should, if possible, be quantitative in order to set an action limit and maximum permissible exposure limit.

\section{MATERIALS AND METHODS}

To model and evaluate the mechanical load of the lumbar spine, we used the ergonomic software "Tecnomatix Classic Jack" (hereinafter Jack), where biomechanical analyses from the Center for Ergonomics at the University of Michigan College of Engineering are implemented. The application makes possible to perform the biomechanical analyses on 3D models of a worker,

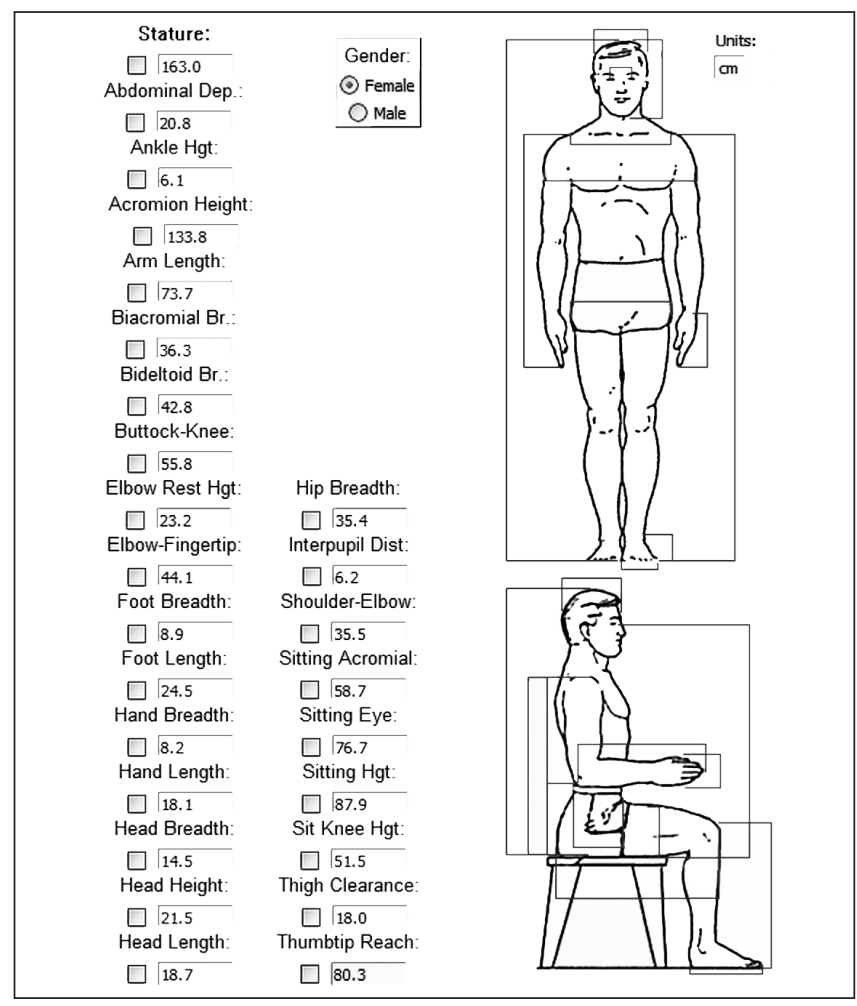

Fig. 1. Anthropometric parameters taken into consideration by Tecnomatix Classic Jack. his/her work environment and the work activity. It simulates mutual relations of those factors and calculates the load of the worker's musculoskeletal system. A human model can either be selected from anthropometric studies built in Jack, or it is possible to create own model based on 26 anthropometric parameters (Fig. 1). Time factors of the work can also be taken into consideration. Physiological limits for load of specific body structures set by the US National Institute for Occupational Health and Safety (NIOSH) are included in the software.

We employed three methods implemented in the Tecnomatix Classic Jack:

Low-Back Analysis uses the biomechanical model of the spine and trunk muscles. It calculates the compression force on the intervertebral disc L4/L5 and compares it with permissible limits recommended by NIOSH. It further calculates shear forces, sagittal, lateral and axial moments (representing the influence of the upper body part and weight of the load on the oblique and rectus abdominis muscles), and traction forces in five dorsal muscle groups. The use of this particular method was crucial for the evaluation of work risk factors and setting of the hygienic criterion.

Static Strength Prediction analyzes tasks involving lifting, lowering, pushing, pulling, and carrying load, rotation and flexion of the trunk during manual work. It calculates force moments in the joints and spine based on anthropometric parameters, position and load. The method is supplemented with the computational module "Force Solver". This module identifies tasks associated with the excess of limits for particular joints, depending on the position, time factors of work (frequency and duration of a task), and the efforts made.

NIOSH Lifting allows analysis of tasks involving symmetrical and asymmetrical manual load lifting. Given the work positions taken during the load lifting and time factors, it evaluates the burden and calculates the recommended weight of the load.

As limits for compressive forces on the L4/L5 disc we used the NIOSH limits set in 1981 and revised in 1991 (8):

- action limit 3,400 N;

- maximum permissible limit 6,400 N.

\section{Procedures and Results}

Step 1: Study of the compressive forces on the L4/L5 disc depending on various work postures and anthropometric parameters - without any effort made.

The crucial factors of work influencing burden of the lumbar spine (work posture, load) were identified and the most important work postures were studied. Based on the metaanalytical study (5), relevant anthropometric parameters were selected according to the ISO/TR 7250-2:2010 (E) standard for European populations (9). The limit values for body height $147-207 \mathrm{~cm}$ and body weight 52-112 kg were chosen to cover the whole Czech working population.

Using the Jack software, 270 animated 3D simulations of various combinations of work postures and anthropometric parameters, which determine compression of the intervertebral disc L4/L5, in the absence of any interfering strength/load were generated (Table 1).

As an example, 3D graph in Fig. 2 demonstrates the compressive forces on the level of intervertebral L4/L5 disc as a function 
Table 1. Input parameters for determining L4/L5 disc compression

\begin{tabular}{|c|c|c|c|}
\hline Postures of trunk & Upper extremities & Angle of stretching arms forward & Anthropometric parameters \\
\hline $\begin{array}{c}\text { Flexion } 0-90^{\circ} \\
\left(\operatorname{step} 5^{\circ}\right)\end{array}$ & $\begin{array}{c}\text { Variants: } \\
\text { a) one arm stretched forward, the } \\
\text { other in neutral position } \\
\left(\text { step } 5^{\circ}\right)\end{array}$ & $\begin{array}{c}\text { Body height } 147-207 \mathrm{~cm} \\
(\text { step } 10 \mathrm{~cm})\end{array}$ \\
\hline $\begin{array}{c}\text { Lateral deviation } 0-20^{\circ} \\
\left(\text { step } 5^{\circ}\right)\end{array}$ & $\begin{array}{c}\text { Body weight } 52-112 \mathrm{~kg} \\
(\text { step } 10 \mathrm{~kg})\end{array}$ \\
\hline
\end{tabular}

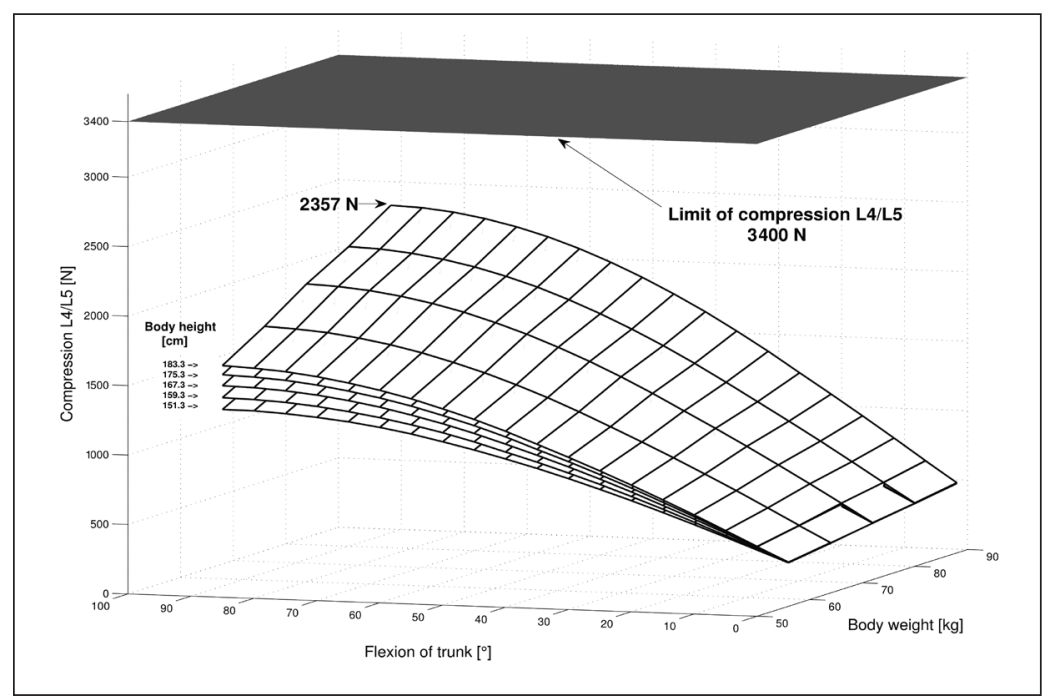

Fig. 2. Computed compression forces (in newtons) on the L4/L5 disc for various combinations of trunk flexion, body weight and height, without any effort made.

Table 2. Computed compression forces (in newtons) on the L4/L5 disc in a subject of $167 \mathrm{~cm}$ for various combinations of trunk flexion and body weight, without any other effort made

\begin{tabular}{|c|c|c|c|c|c|}
\hline \multirow{3}{*}{ Flexionof trunk $\left[{ }^{\circ}\right]$} & \multicolumn{5}{|c|}{ Height of model women $167.3 \mathrm{~cm}$} \\
\hline & \multicolumn{5}{|c|}{ Body weight [kg] } \\
\hline & 56 & 64 & 72 & 80 & 88 \\
\hline 0 & 316 & 360 & 406 & 454 & 503 \\
\hline 5 & 413 & 468 & 526 & 585 & 645 \\
\hline 10 & 509 & 575 & 643 & 714 & 786 \\
\hline 15 & 603 & 679 & 758 & 840 & 923 \\
\hline 20 & 694 & 781 & 871 & 963 & 1,056 \\
\hline 25 & 783 & 879 & 979 & 1,081 & 1,185 \\
\hline 30 & 867 & 973 & 1,082 & 1,197 & 1,315 \\
\hline 35 & 947 & 1,062 & 1,185 & 1,311 & 1,439 \\
\hline 40 & 1,023 & 1,150 & 1,282 & 1,419 & 1,557 \\
\hline 45 & 1,095 & 1,233 & 1,374 & 1,518 & 1,664 \\
\hline 50 & 1,164 & 1,309 & 1,456 & 1,610 & 1,763 \\
\hline 55 & 1,226 & 1,378 & 1,532 & 1,692 & 1,852 \\
\hline 60 & 1,280 & 1,437 & 1,599 & 1,763 & 1,931 \\
\hline 65 & 1,329 & 1,489 & 1,655 & 1,824 & 1,998 \\
\hline 70 & 1,368 & 1,532 & 1,703 & 1,878 & 2,053 \\
\hline 75 & 1,400 & 1,566 & 1,740 & 1,918 & 2,096 \\
\hline 80 & 1,422 & 1,592 & 1,767 & 1,946 & 2,128 \\
\hline 85 & 1,437 & 1,609 & 1,783 & 1,964 & 2,147 \\
\hline 90 & 1,443 & 1,614 & 1,790 & 1,969 & 2,152 \\
\hline
\end{tabular}


of the trunk flexion $0-90^{\circ}$ with step $5^{\circ}$, body weight $56-88 \mathrm{~kg}$ with step $8 \mathrm{~kg}$, and body heights $151 \mathrm{~cm}, 159 \mathrm{~cm}, 167 \mathrm{~cm}, 175$ $\mathrm{cm}$, and $183 \mathrm{~cm}$. The upper extremities were in a perpendicular position and stretched. The dark gray plane in the chart corresponds with the first limit value of 3,400 $\mathrm{N}$ for the compression of the L4/L5 disc. Other planes depict the dependence of computed compression values on various combinations of the above-mentioned factors.

It can be seen that the dependence of the L4/L5 disc compression on the trunk flexion and body height is nonlinear, while the dependence on the body weight is linear. Because the individual planes in 3D graph in Fig. 2 show similar shapes, the dependence of compression on the various trunk flexion and body weight combinations is similar. This allowed us to reduce the number of studied simulations.

Within the ranges of body height and weight depicted in Fig. 2, and without any load, the limit of the L4/L5 disc compression, i.e. $3,400 \mathrm{~N}$, was not exceeded even during the trunk flexion of $90^{\circ}$.

The numerical values of the compression force for a subject with body height of $167 \mathrm{~cm}$ are presented in Table 2 .

Step 2: Study of the compressive forces on the L4/L5 disc depending on various work postures and anthropometric parameters - during an effort.

In more than 1,000 simulations we studied the influence of manual material handling and making muscular efforts in combi- nation with various work postures and anthropometric parameters on the L4/L5 disc compression. We also studied the influence of space location of the origin of force and its orientation on the L4/ L5 disc compression. To measure the distance, we used the $\mathrm{C} 7$ vertebra as a reference point. The parameters describing the space location of force/load in relation to the $\mathrm{C} 7$ vertebra are shown in Fig. 3. The values of space parameters and acting forces magnitude are specified in Table 3.

Fig. 4 shows how the compressive force on the L4/L5 disc depends on the place of origin of the acting force and on its magnitude, given the orientation of the force downwards. The influence of anthropometric parameters and work postures has not been taken into consideration. The two planes in the graph depict the dependence of calculated compressive values for acting forces of $250 \mathrm{~N}$ and $500 \mathrm{~N}$. The corresponding numerical values are presented in Table 4.

It is evident from the 3D graph in Fig. 4 that the compression increases linearly depending on the distance from the place of origin of the acting force (Fig. 3, distances A and B). It also increases linearly with the acting force.

Table 4 shows how the compressive force on the L4/L5 disc depends on the place of origin of the acting force for specific magnitude of the force $=250 \mathrm{~N}$, given its orientation downwards. The influence of anthropometric parameters and postures is not taken into consideration.

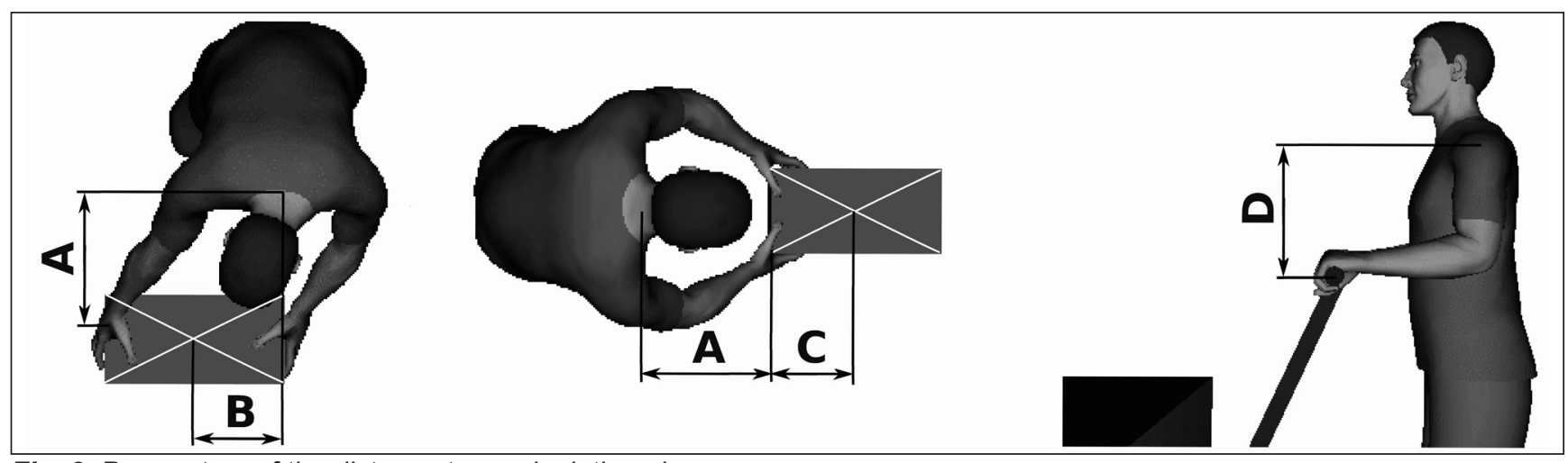

Fig. 3. Parameters of the distance to manipulation plane.

Table 3. Parameters for estimation of the L4/L5 disc compression depending on the magnitude, orientation and place of operation of the force/load

\begin{tabular}{|c|c|}
\hline \multicolumn{2}{|l|}{ Forces acting vertically - up and down } \\
\hline Space location of the origin of force & Magnitude of acting force \\
\hline Distance of the origin of force from L4/L5 forward (distance A) 0-70 cm (step $10 \mathrm{~cm})$ & $0-500 \mathrm{~N}($ step $10 \mathrm{~N})$ \\
\hline Distance of the origin of force from L4/L5 laterally (distance B) 0-70 cm (step $10 \mathrm{~cm}$ ) & $0-500 \mathrm{~N}(\operatorname{step} 10 \mathrm{~N})$ \\
\hline Combination of distances from the place of origin of force (distance A and B), (step $10 \mathrm{~cm})$ & $0-500 \mathrm{~N}(\operatorname{step} 10 \mathrm{~N})$ \\
\hline \multicolumn{2}{|l|}{ Forces acting horizontally - pulling and pushing } \\
\hline Space location of the origin of force & Magnitude of acting force \\
\hline Distance of the origin of force from L4/L5 laterally (distance B) 0-70 cm (step $10 \mathrm{~cm}$ ) & $0-500 \mathrm{~N}(\operatorname{step} 10 \mathrm{~N})$ \\
\hline $\begin{array}{l}\text { Height of the origin of force between the upper extremities at shoulder level and stretched perpendicularly down (distance D) } \\
0-70 \mathrm{~cm}(\operatorname{step} 10 \mathrm{~cm})\end{array}$ & $0-500 \mathrm{~N}(\operatorname{step} 10 \mathrm{~N})$ \\
\hline Combination of distances from the place of origin of force (distances B and D) step $10 \mathrm{~cm}$ & $0-500 \mathrm{~N}($ step $10 \mathrm{~N})$ \\
\hline
\end{tabular}

Distance A: Horizontal distance between the C7 vertebra and the midpoint of the palm (grasp)

Distance B: Horizontal distance between the load centre of gravity and the $\mathrm{C} 7$ vertebra

Distance C: Horizontal distance between the load centre of gravity and the midpoint of the palm (grasp)

Distance D: Vertical distance between the midpoint of the palm and the midpoint of the shoulder joint 
Based on the results of the above-described simulations, we determined the following parameters with crucial influence on resulting load of the lumbar spine:

- Anthropometric parameters - body height and weight;

- Trunk posture - combination of ventral and lateral flexion and rotation;

- Posture of the upper extremities;

- Manner of manipulation/force operation - whether done by one or both upper extremities or with one upper extremity supported;

- Distance of the load centre or the origin of force (Fig. 3, distances A, B, C, and D);

- Magnitude of the acting force/mass of the load;

- Force orientation (vertically/horizontally).

Step 3: Development of the computational module

As the final output of our study we used software for the computational module. It incorporates a database of the results of simulations of the L4/L5 disc compression for various combinations of the above-mentioned parameters. Based on this data and the values of specific input parameters for particular worker and work operations, the software calculates the value of the L4/
L5 disc compression. We collect the input parameters using the checklist that is described under Step 6. The critical work operations exceeding the limit values can be identified this way.

Fig. 5 shows a screenshot of evaluation by the computational module of some working tasks in a healthcare worker. In the upper part of the screen, there are entry fields, in the lower part there are results for 12 work operations. It can be seen that the limit of compression, i.e. 3,400 N, was exceeded during the operation No. 2 (manual handling of a patient in bed), No. 5 and 6 (lifting of a patient in bed) and No. 9 and 10 (handling of a patient on a wheelchair)

Step 4: Generation of the graphic maps

A special component of the computational module is a generator of graphic maps. The maps enable the synoptic presentation of results. In the graphic maps, various bands of the compression values are marked with a grayscale: $0-3,400 \mathrm{~N}$ light gray, 3,400-6,400 N medium gray, and 6,400 N dark gray.

The maps depict the L4/L5 disc compression values for various types of work posture, work load (the weight of the burden, manipulation force, distance from material, distance from manipulation plane, etc.), and the time aspects of particular work operation.

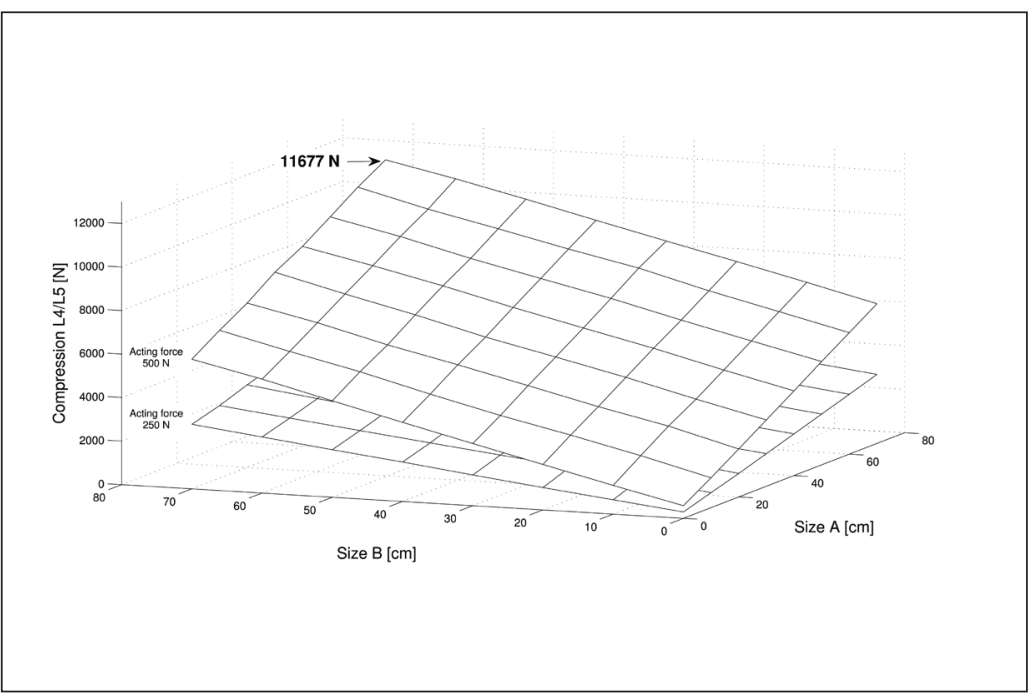

Fig. 4. Computed compression of the L4/L5 disc (in newtons) depending on the magnitude of exerted force and its place of origin.

Table 4. Computed compression forces (in newtons) on the L4/L5 disc caused by the acting force of $250 \mathrm{~N}$ at various combinations of the place of origin of force

\begin{tabular}{|c|c|c|c|c|c|c|c|c|}
\hline & \multicolumn{9}{|c|}{ Acting force = 250 N } \\
\hline \multirow{2}{*}{ Size A [cm] } & \multicolumn{9}{|c|}{ Size B [cm } \\
\cline { 2 - 12 } & $\mathbf{0}$ & 10 & $\mathbf{2 0}$ & $\mathbf{3 0}$ & $\mathbf{4 0}$ & $\mathbf{5 0}$ & $\mathbf{6 0}$ & $\mathbf{7 0}$ \\
\hline 0 & 290 & 660 & 1,026 & 1,410 & 1,812 & 2,184 & 2,575 & 2,967 \\
\hline 10 & 682 & 1,131 & 1,497 & 1,833 & 2,201 & 2,574 & 2,953 & 3,332 \\
\hline 20 & 1,079 & 1,528 & 1,909 & 2,293 & 2,658 & 2,978 & 3,355 & 3,795 \\
\hline 30 & 1,496 & 1,877 & 2,313 & 2,675 & 3,044 & 3,471 & 3,838 & 4,220 \\
\hline 40 & 1,913 & 2,299 & 2,779 & 3,104 & 3,475 & 3,877 & 4,247 & 4,577 \\
\hline 50 & 2,333 & 2,725 & 3,092 & 3,524 & 3,912 & 4,274 & 4,670 & 5,030 \\
\hline 60 & 2,752 & 3,146 & 3,638 & 4,013 & 4,325 & 4,712 & 5,068 & 5,463 \\
\hline 70 & 3,173 & 3,566 & 3,937 & 4,388 & 4,741 & 5,119 & 5,497 & 5,866 \\
\hline
\end{tabular}


One point in the map represents the calculated value of the L4/L5 disc compression in a worker of given body height and weight.

For the sake of clarity, Fig. 6 shows just one structural block of complete graphic map. The horizontal bars correspond to the trunk flexion of $0-90^{\circ}$, with step $5^{\circ}$ from the above downwards. The vertical lines delimit the body height range from 137-217 $\mathrm{cm}$, body weight is specified below the graph).

The complete graphic maps contain five rows; each of them consisting of 17 blocks described above. Each of the five rows is calculated for a specified value of other studied factors, e.g. for the weight of handled material in Fig. 7, for various distances to the manipulation plane in Fig. 8, and for various values of the time coefficient in Fig. 9. Therefore, relations of four factors influencing the compression of the L4/L5 disc can be analyzed simultaneously.

Step 5: Estimation of time and frequency correction coefficients for limits of compressive forces

In accordance with the Czech legislation (10) and European standards (12), we determined the following time and frequency limits for work operations causing the L4/L5 disc compression $3,400-6,400 \mathrm{~N}$ :

- 250 work operations per shift $(11,12)$;

- 30 minutes of the cumulative duration of individual operations per shift (10-12).

We apply the limits in two ways (Fig. 10):

For the working load with compression on the L4/L5 disc of 3,400 $N$ at the maximum

The limits need to be adjusted according to time aspects of work (duration of a task and its frequency during a shift). To take into consideration time factors, we proposed correction coefficients defined in Table 5. The estimation of coefficients was based on the graphic maps (Step 4).

To calculate compression limit with regard to time factors, we use the following formula:
Compression limit $=3,400 \mathrm{~N} /$ time or frequency coefficient (the higher of the two)

For the working load with the compression on the L4/L5 disc of $3,400-6,400 \mathrm{~N}$

The limit value of compression on the disc L4/L5 is inversely related to frequency of the task and/or to cumulative duration of the task per shift (the hyperbolic course of the curve in Fig. 10). This holds true for the task repetition of 10-250 and for its cumulative duration of 1.2-30 minutes per shift.

Step 6: Checklists for the collection of data on hazardous work activities

To collect the input data for the computational module calculating compression forces on the L4/L5 disc in particular workers, we have prepared checklists as well as a guideline for the evaluation of work activities in the field settings. The checklists are focused on hazardous work identified through the graphic maps as significantly overloading the low-back region and potentially exceeding the compression limit of 3,400 N or even 6,400 N. Entries into the checklists include body height, body weight, ventral and lateral trunk flexion, posture of the upper extremities, type of manipulation, distance of the load (A), distance of the load centre from manipulation plane (B), distance of the load centre from the place of grip $(\mathrm{C})$, mass of the load, magnitude of the acting force, force orientation (vertically or horizontally), frequency of the work operations per shift, and total duration of work operation during a shift (for definition of the distances see Fig. 3). The measurement and assessment of various work and anthropometric parameters is performed according to the methodology described in the Government Regulation No. 361/2007 Coll. (10) and in agreement with the harmonized methodical standard CSN EN 1005 (12). Obtaining and collecting data and then filling in the questionnaire takes on average half a day to two working days.

Data from checklists are entered into the computational module, which calculates compression force on the L4/L5 disc (Step $3)$. The resulting value is compared with compression limits

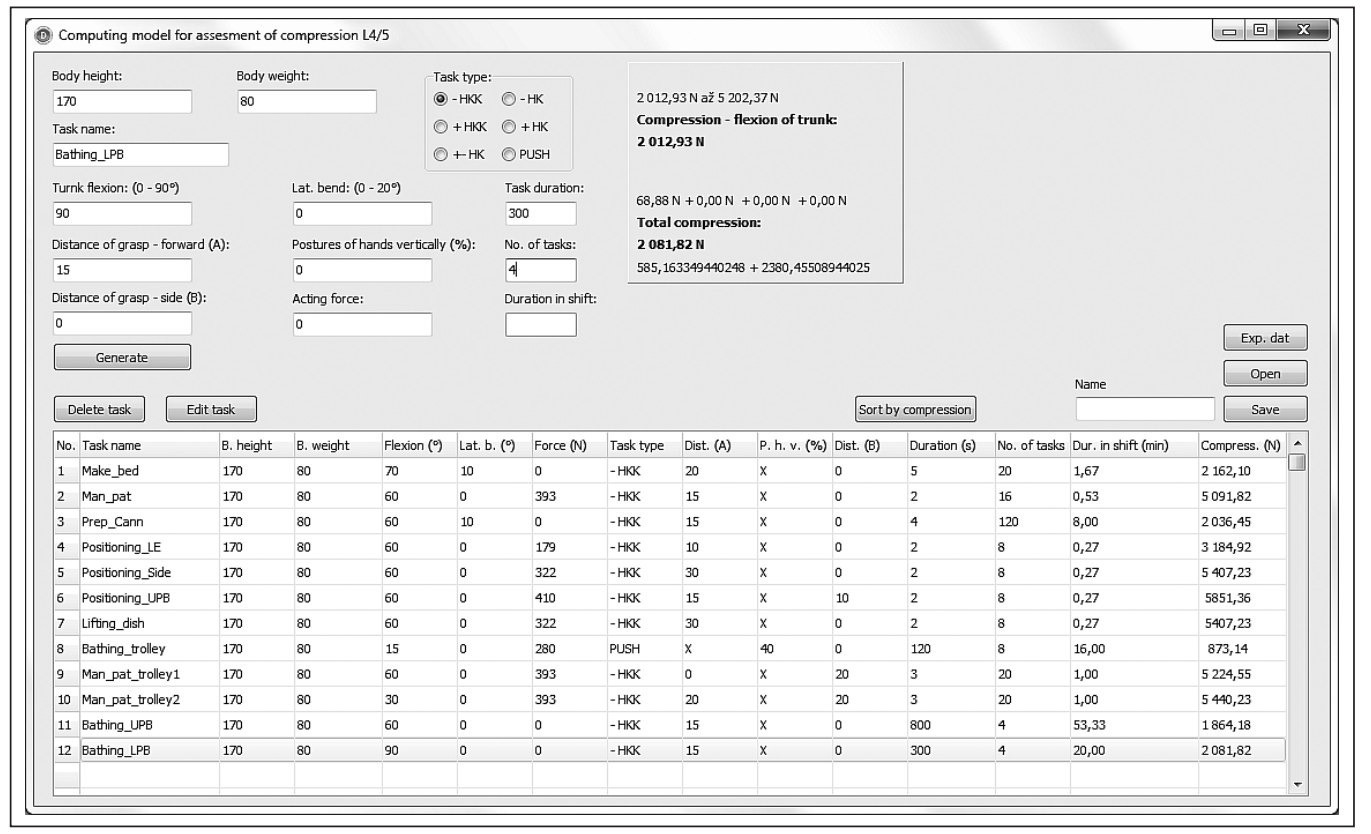

Fig. 5. Analysis of work operations in a healthcare worker using the computational module. 
Table 5. Correction coefficients for limits of compressive forces

\begin{tabular}{|c|c|c|c|}
\hline Frequency of the task & or Duration of the task & Coefficient & Limit for compressive forces (N) \\
\hline $250-375$ & $30-45 \mathrm{~min}$. & 1.0 & 3,400 \\
\hline $375-500$ & $45-60 \mathrm{~min}$. & 1.1 & 3,091 \\
\hline$>500$ & $>60 \mathrm{~min}$. & 1.2 & 2,833 \\
\hline
\end{tabular}

adjusted for time and frequency aspects of the work operation (Step 5).

\section{DISCUSSION}

The aim of the study was to develop a computational module for the prediction of compressive force on the L4/L5 disc. The module should be used in the process of incorporating low-back disorders into the list of occupational diseases in the Czech Republic.

The problem is complex and it is not possible to address it in its entirety. Therefore, we chose just one factor, namely the compressive force on the L4/L5 disc caused by particular work activity, as a proxy quantitative measure of the risk of damage to

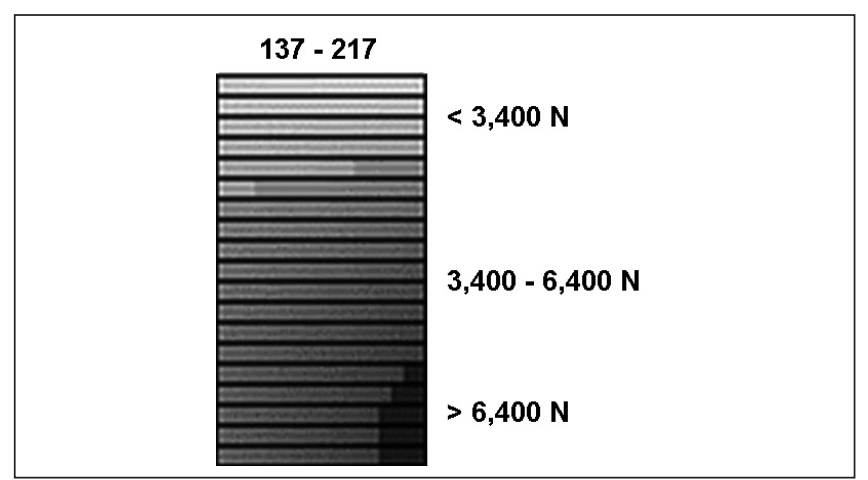

Fig. 6. One block of the graphic map. the low-back by manual work. This force is considered a critical stress vector and good predictor of low-back damage (13). The values calculated by an equation published in the NIOSH Work Practices Guide for Manual Lifting (1981, revised in 1991) were accepted as limits for the compressive forces on the disc L4/L5, i.e. the action limit of $3,400 \mathrm{~N}$ and the maximum permissible limit of $6,400 \mathrm{~N}(8)$. Although some authors question the substantiation of the limit (14), it is widely accepted and used. The limit is also implemented in the Tecnomatix Jack.

According to Sue et al. the limit value of $3,400 \mathrm{~N}$ is acceptable for $75 \%$ of women workers and $99 \%$ of men workers, while the value of $6,400 \mathrm{~N}$ is acceptable only for $1 \%$ of women and $25 \%$ of men. The work activities causing the compressive forces on the L4/L5 disc below 3,400 $\mathrm{N}$ are considered as low risk, compressive forces between $3,400 \mathrm{~N}$ and $6,400 \mathrm{~N}$ as medium risk, and above $6,400 \mathrm{~N}$ as high risk for damage to the lumbar spine (15).

The load-bearing capacity of the lumbar vertebrae is influenced by age and gender (16). Concerning the age, there is an inverse relation - the capacity is decreasing with age. Using the regression equation for the relation between load-bearing capacity of the lumbar disc and age, as published by Jäger (16), we can predict that the capacity would decrease to the value of $3,400 \mathrm{~N}$ in the age of 77 years in man and 63 years in women. Our provisional inclusion age criterion for consideration of the lumbar spine disorders as occupational diseases is $\leq 55$ years, therefore, we do not take age into consideration. We also made a pilot comparison of results for men and women. The observed differences were small and inconsistent. This might be related to the fact that the Tecnomatix

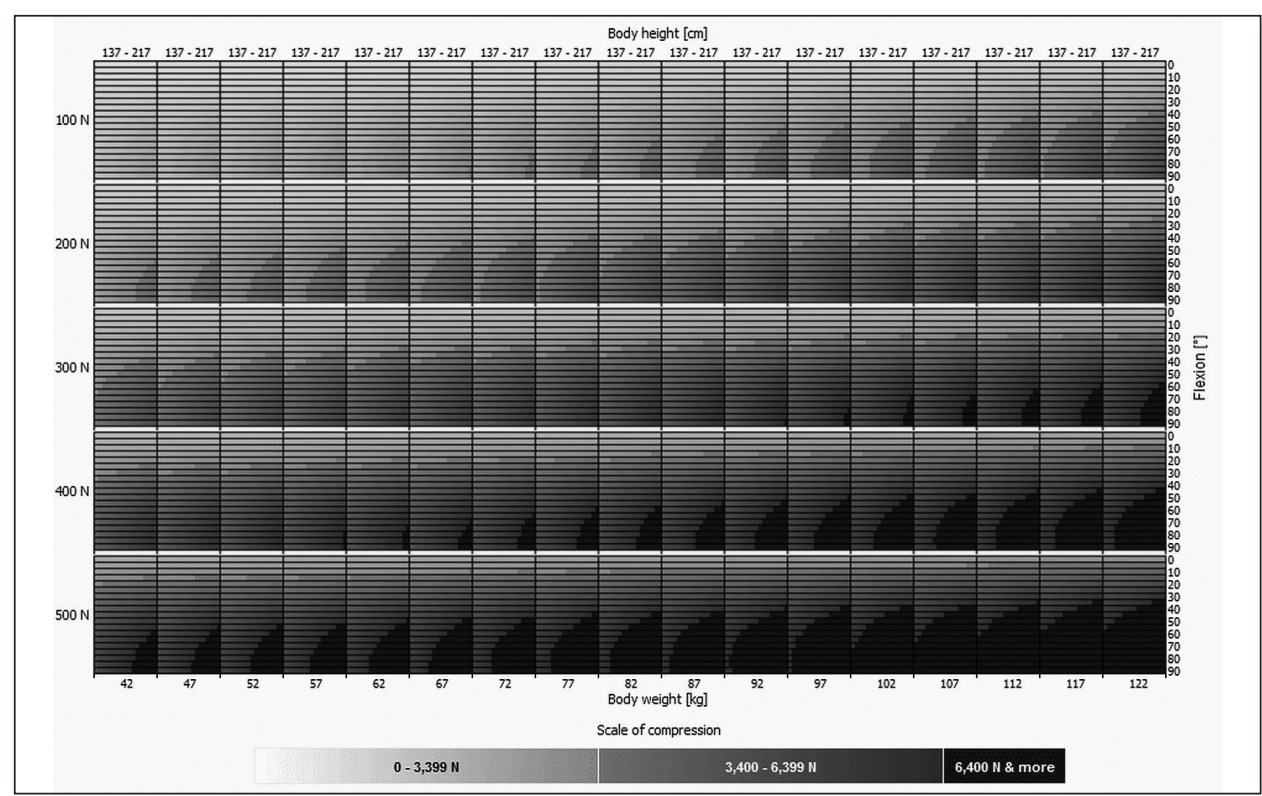

Fig. 7. Graphic presentation of the L4/L5 disc compression values for various combinations of body weight, body height, trunk flexion, and manipulated load 100-500 N (step $100 \mathrm{~N}$ ), given parameters of distance to the manipulation plane $A=20 \mathrm{~cm}, B$ $=0 \mathrm{~cm}$, and time coefficient $=1$. 


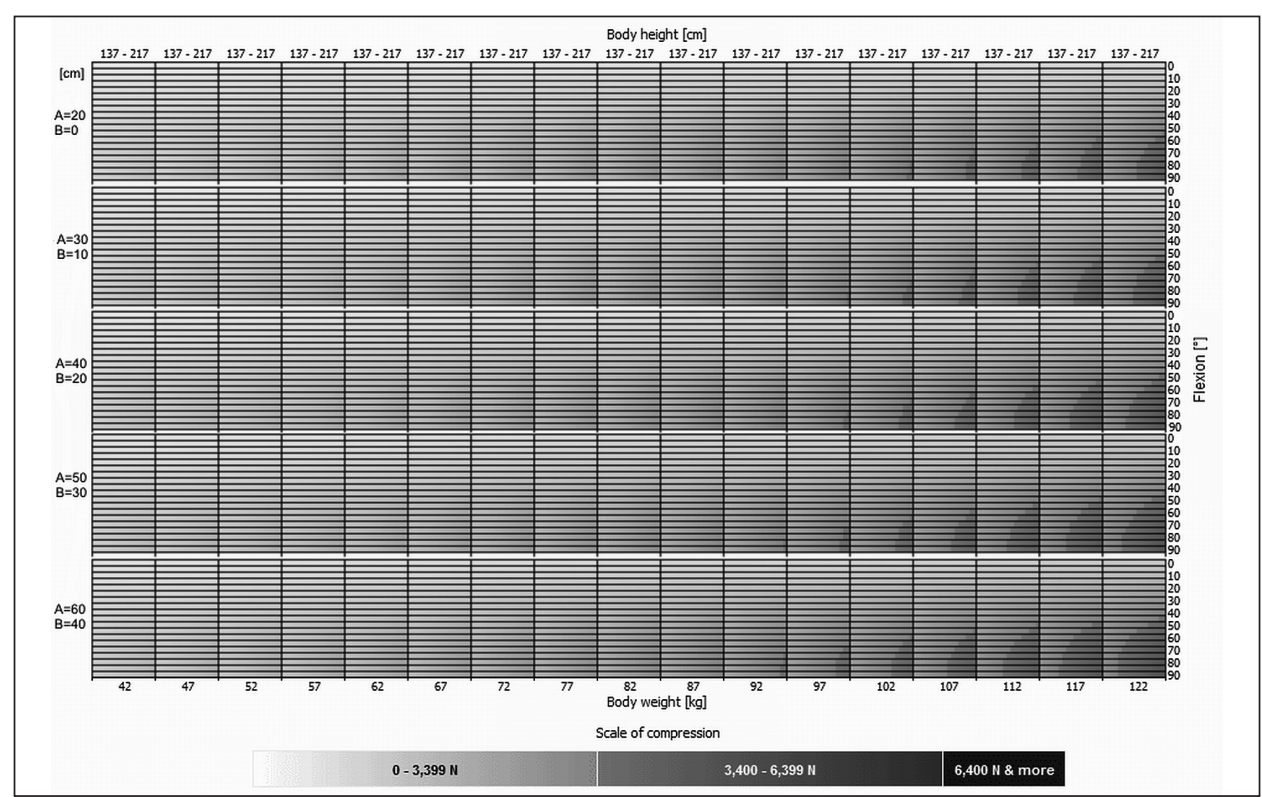

Fig. 8. Graphic presentation of the L4/L5 disc compression values for various combinations of body weight, body height, trunk flexion, and various distances to the manipulation plane, given weight of the manipulated load $=10 \mathrm{~N}$, and time coefficient $=1$.

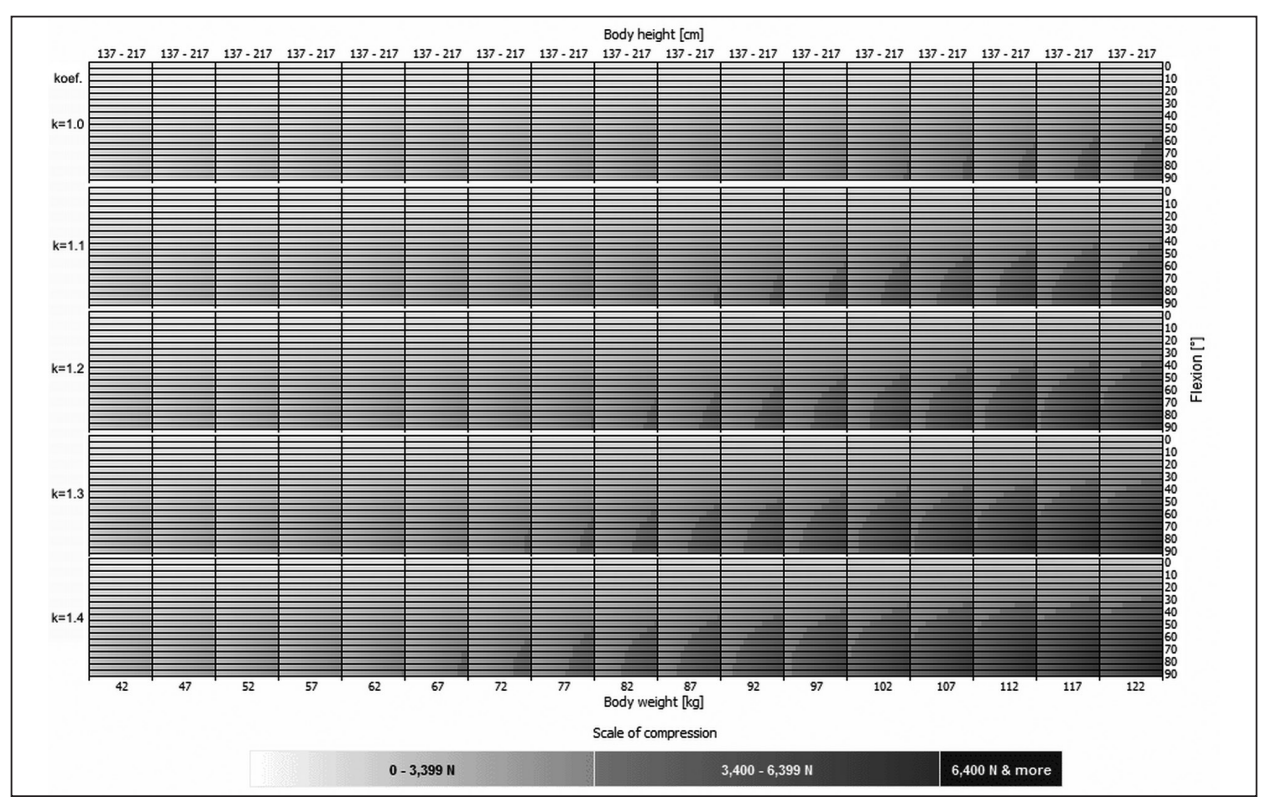

Fig. 9. Graphic presentation of the L4/L5 disc compression values for various combinations of body weight, body height, trunk flexion, and time coefficient, given distances to the manipulation plane $A=40 \mathrm{~cm}, B=20 \mathrm{~cm}$, and weight of the manipulated load $=10 \mathrm{~N}$.

Jack takes into account the anthropometric genders differences. Thus, we did not set special limit values for men and women.

To estimate the compression value on an individual level, we developed a computational module based on the ergonomic software Tecnomatix Classic Jack allowing the use of specific input parameters for particular worker and his/her work activity. With Jack, we calculated compressive forces on the L4/L5 disc in about 1,300 simulated situations for combinations of various factors supposed to influence the force (Steps 1 and 2). The parameters, which on the basis of simulations or epidemiological studies appeared to be crucial for the compression of the L4/L5 disc, were built in the computational algorithm as a tool for the use in field settings (Step 3). The input data for the computation were collected using the checklists (Step 6). A similar problem was encountered by Ditchen et al. (17) who developed 11 equations for the estimation of compressive force on the lumbar discs in order to replace the use of expensive and time-consuming "Der Dortmunder" biomechanical simulation model in field settings.

The above-mentioned NIOSH Work Practices Guide for Manual Lifting (8) is mainly intended for the risk control and prevention of health damage. Although we also acknowledge the importance of prevention, the main purpose of our work was different - it focused on the exposure criteria for recognizing dorsopathies as occupational diseases with entitlement to compensation. Thus our goal was not solely medical but also medico-legal. We strove to find a decisive criterion for the risk of low-back damage and severity of exposure in order to recognize the spine disorder as an occupational disease. We are aware of the fact that the criterion 


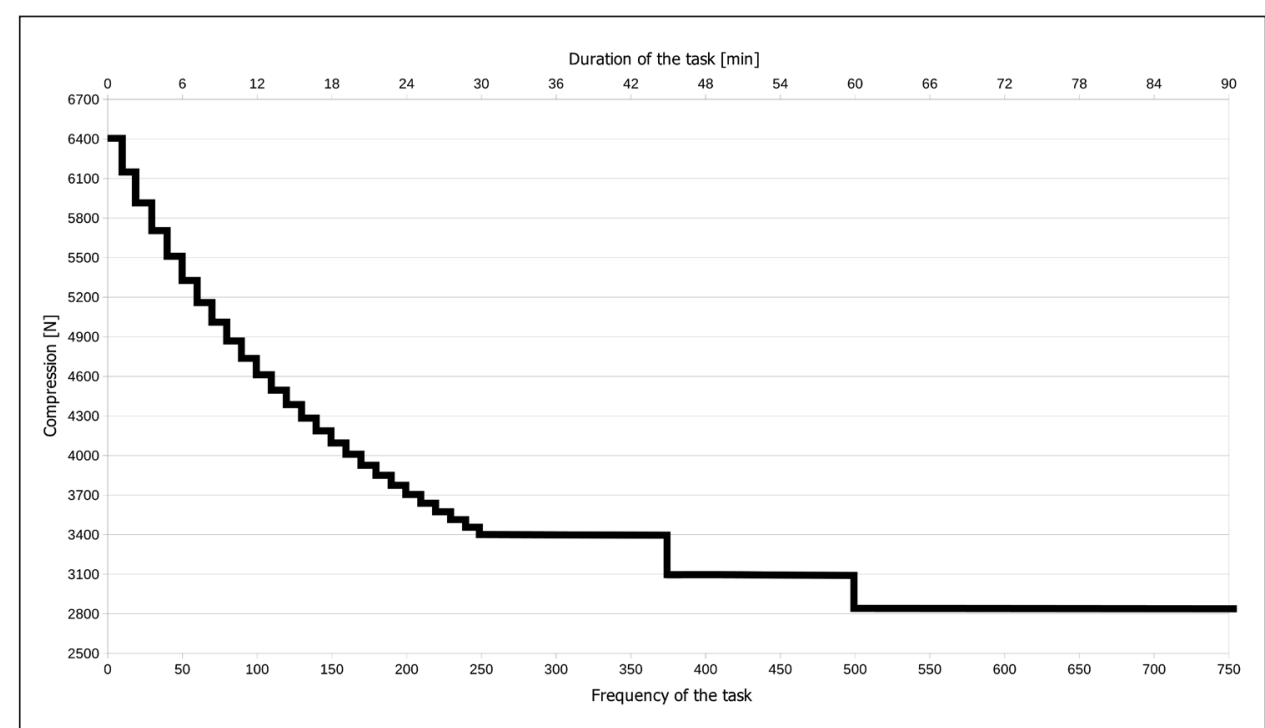

Fig. 10. Dependence of the compressive force limit value on the task frequency and duration.

is not causal. Meeting the criterion does not necessarily mean that the health problems were caused by overexertion, and on the other hand, the problems may be due to overexertion, though the criterion was not met. The criterion is inevitably associated with the risk of false positivity as well as false negativity.

Nevertheless, our results can be also used for the recommendation of preventive measures to decrease the health risk in occupations associated with overload of the low-back region. Graphic maps produced as by-products of the computational module serve the purpose (Step 4). The maps enable clear and fast analysis of particular workplace in order to identify work tasks hazardous for the low-back spine, as well as the subgroups of workers for whom the particular work task would be hazardous. We can also define the limit values for particular types of work tasks through the analysis and visualization of compression values in the graphic maps.

The graphic maps also enable us to control the algorithm used in the computational model. If there is an error in the algorithm or the input data, then an anomaly may appear in the map, such as an isolated spot of hue differing from the background hue in particular area of the map. Maps can be used for setting the evaluation criteria as well as time and frequency coefficients (Step 5).

There are also limitations to the study. We studied just one factor hazardous for low-back disorders, namely mechanical overexertion. In order to make the study feasible, we intentionally disregarded factors such as the whole body vibration or psychophysical factors, e.g. mental stress and lifestyle factors. We plan to study the other factors and their interactions in the future. Nevertheless, mechanical overexertion was not examined comprehensively. Besides other things, we did not take into consideration factors such as sagittal and lateral shear forces for reasons similar to those described by Jäger et al. (18).

We are also aware that even though the method seems to be working well in the laboratory conditions, it may not do so in the field settings. In reality, the data entering into the computational module will be frequently based on rather rough measurements. Consequently, the predicted compressive values will be inevitably burdened with some uncertainty. Nevertheless, we believe that the estimates of the low back burden provided by our method approximate the real values closest of all the in vivo methods currently available.

To summarize, we propose that the "hygienic criterion" to recognize low-back disorders as occupational diseases should be met if in a worker the compression force on the L4/L5 disc predicted by the developed computational module exceeds the $\mathrm{NIOSH}$ limit value of $3,400 \mathrm{~N}$ adjusted for time and frequency aspects of the particular work activity.

Testing the validity of the proposed method is in progress. Some parameters of the computational module will be probably adjusted (especially the proposed compression limits, and time and frequency correction coefficients).

\section{Acknowledgements}

The study was supported by grant: IGA MZ NT/14471-3.

\section{REFERENCES}

1. Kuiper JI, Burdorf A, Frings-Dresen MH, Kuijer PP, Spreeuwers D, Lötters FJ, et al. Assessing the work-relatedness of nonspecific low-back pain. Scand J Work Environ Health. 2005 Jun;31(3):237-43.

2. Gourmelen J, Chastang JF, Ozguler A, Lanoë JL, Ravaud JF, Leclerc A. Frequency of low back pain among men and women aged 30 to 64 years in France. Results of two national surveys. Ann Readapt Med Phys. 2007 Nov;50(8):640-4, 633-9.

3. Plouvier S, Gourmelen J, Chastang JF, Lanoë JL, Leclerc A. Low back pain around retirement age and physical occupational exposure during working life. BMC Public Health. 2011 Apr 28;11:268. doi: 10.1186/1471-2458-11-268.

4. Deyo RA, Weinstein JN. Low back pain. N Engl J Med. 2001 Feb 1;344(5):363-70.

5. Lötters F, Burdorf A. Prognostic factors for duration of sickness absence due to musculoskeletal disorders. Clin J Pain. 2006 Feb;22(2):212-21.

6. Commission Recommendation of 19 September 2003 concerning the European schedule of occupational diseases (2003/670/EC). Off J Eur Union. 2003 Sep 25;46(L 238):28-34.

7. Government Regulation No. 290/1995 Coll., Annex 1, as amended, which determines List of occupational diseases. Sbírka zákonů ČR. 1995 Dec 15;Pt 76:3968-78. (In Czech.)

8. Waters TR, Putz-Anderson V, Garg A, Fine LJ. Revised NIOSH equation for the design and evaluation of manual lifting tasks. Ergonomics. 1993 Jul;36(7):749-76.

9. ISO/TR 7250-2. Basic human body measurements for technological design - Part 2: Statistical summaries of body measurements from national populations. Geneva: International Organization for Standardization; 2010 . 
10. Government Regulation No. 361/2007 Coll., which determines conditions of health protection at work. Sbírka zákonů ČR. 2007 Dec 28;Pt 111:5086-5236. (In Czech.)

11. Occupational diseases ruling - Occupational diseases leaflets. Decree No. 2108 of the Ministry of Labour and Welfare of September 1, 2006. Bundesarbeitsblatt. 2006;(10):30. (In German.)

12. ČSN EN 1005-4+A1. Safety of machinery - Human physical performance - Part 4: Evaluation of working postures and movements in relation to machinery. Prague: Czech Office for Standards, Metrology and Testing; 2009. (In Czech.)

13. Herrin GD, Jaraiedi M, Anderson CK. Prediction of overexertion injuries using biomechanical and psychophysical models. Am Ind Hyg Assoc J. 1986 Jun;47(6):322-30.

14. Jäger M, Luttmann A. Critical survey on the biomechanical criterion in the NIOSH method for the design and evaluation of manual lifting tasks. Int J Ind Ergon 1999;23(4):331-7.

15. Ferguson SA, Marras WS, Burr D. Workplace design guidelines for asymptomatic vs. low-back-injured workers. Appl Ergon. 2005 Jan;36(1):85-95.
16. Jäger M, Luttmann A, Göllner R. Load-bearing capacity of the lumbar spine for manual materials handling - derivation of the „Dortmund Recommendations " based on the lumbar compressive strength. Zentralbl Arbeitsmed Arbeitsschutz Ergonomie. 2001;51(8):354-72. (In German.) 17. Ditchen D, Lunderhausen N, Bergmann A, Bolm-Audorff U, Haerting J, Haufe E, et al. Assessment of lumbar-disc compressive forces in German occupational disease no. 2108. Development of an instrument within the EPILIFT Exposure Criteria Study. Zentralbl Arbeitsmed Arbeitsschutz Ergonomie. 2014;64(4):258-69. (In German.)

18. Jäger M, Geiß O, Bergmann A, Bolm-Audorff U, Ditchen D, Ellegast R, et al. Biomechanical analyses on lumbar load within the German Spine Study. Zentralbl Arbeitsmed Arbeitsschutz Ergonomie. 2007;57(9):26476. (In German.)

Received March 5, 2015 Accepted in revised form August 6, 2015 